\title{
Research on the Inheritance and Development Strategies of Zhuang Folk Songs in the Song Creation*
}

\author{
Huiling Wei \\ Hechi University \\ Hechi, China
}

\begin{abstract}
In recent years, as China gradually enhances the awareness of cultural development and inheritance, the protection of intangible cultural heritage has been strengthened, and minority culture with local characteristics has become the focus of cultural protection. Therefore, in order to further ensure the inheritance and development of minority culture, based on clarifying the characteristic forms which the Zhuang folk songs provide to the song creation, this paper analyzes the inheritance problems of Zhuang folk songs from the perspective of song creation, and explores the ways and means of inheriting and developing Zhuang folk songs in song creation with the thinking of song creation.
\end{abstract}

Keywords-Zhuang Folk Songs; song creation; inheritance; development

\section{INTRODUCTION}

Singing is an indispensable part in the life of Zhuang nationality and dancing also becomes an important way of their cultural activities. Based on this condition, this paper aims to achieve the inheritance and development of Zhuang folk songs, and explores the special inheritance role of Zhuang nationality on the song creation. In the process of studying the problems that folk songs inheritance had faced, this paper also studies the scientific strategies to inherit and protect Zhuang folk songs to promote the inheritance and development of Zhuang folk songs.

\section{THE SPECIAL Forms THAT ZHUANG FolK SONGS HAVE PROVIDED FOR THE SONG CREATION}

Zhuang folk songs have many types and are the crystallization of working people's wisdom. And the highly distinctive types of songs also bring new creative thinking for the song creation. Specifically, according to the different types of songs, the inspirations that Zhuang folk songs have brought for the song creation can be divided into the following aspects: Grievances-expressing Song of Zhuang Nationality

Grievances-expressing song is a form of expression of

*Fund Program: "Research on the Reform of Teaching Mode of Song Creation Course in Local Colleges under the Background of Innovation and Entrepreneurship" of 2018 Education and Teaching Reform Project in Hechi University, Project No.: 2018EA015. songs with special features in Zhuang folk songs and includes grievances-expressing song for long-term hired hand, for wife, for single man, for sighing with feeling and for destiny and so on. This kind of song thinking shows life's miseries by means of song, which can wonderfully stimulate emotion of listener who can relax their stress. Therefore, the combination of grievances-expressing and creation makes annoyance songs for husbandman, integrates positive guiding thoughts. It can relax husbandman's stress, improve people's enthusiasm for life, and become an important means for artistic sublimation. The expansion of audience and huge singing form of songs usually meet the demands of different people in different ages. Therefore, this kind of songs can get recognition from audience in spiritual and emotional level, nurture the development of Zhuang folk songs and promote the development and innovation of the song creation.

\section{A. Love Song of Zhuang Nationality}

As a kind of song genre to express love for the beloved, the love song of Zhuang nationality even can bring totally different creative thinking for the song creation. This type of song mainly aims to express the words right from one's heart, so its melody is mild and indirect and flexible, soulful and fine and smooth. In terms of the form of expression, it mainly takes antiphonal style to interact with the other party and contact with both parties who express their sadness of separation, which enhances the musical interactivity and improves feeling's communication. Because the young men of Zhuang nationality are edified by the folk songs, their artistic creativity and innovation are outstanding. Therefore, they often sing spontaneously when expressing their thoughts and feelings, which enrich the varieties of the song creation, makes songs activate and close to life, and better express deep feelings and sincere love.

\section{B. Folk Custom Song of Zhuang Nationality}

As one of the national minorities in China, Zhuang nationality has their own special manners and customs. These songs, such as celebrating song, benison song, toasting song, welcome song, mountain song, seeing-off song in festivals, ceremony song for ceremony of blessing, wailing song and wedding song in weddings and funerals, have local features and special artistic attraction. The different song 
genres, such as congratulations and celebrations and welcoming and seeing off have great significance in the song creation. It can broaden the new methods for the song creation, promote the combination of special manners and customs of Zhuang nationality and modern musical creation, create a creative thinking of Zhuang folk songs suitable for the development of modern society, and promote the development and inheritance of Zhuang folk songs. Take the mountain song for example, and the mountain song can be divided into different areas, such as Huan, Xi, Jia, Bi and Lun, and different areas have some differences in the singing style, for example, Huan area adopts narrative method to sing. Although mountain song has different sing forms, the mountain song of Zhuang nationality integrates leading singing, chorus and ensemble and other basic forms in the basic procedures and models, and the various songs of Zhuang nationality form pluralism tunes of mountain songs of Zhuang nationality.

\section{Working Song of Zhuang Nationality}

The working song is a kind of singing form of folk song spread by Zhuang nationality to cultivate their taste and relax their mind in the hard labor life. The words and phrases of working song not only reflect people's devotion to life and labor, but also reveal their life fun in the labor life, and some of songs even become the ballad with color life.

In the long development history of Zhuang nationality, the working song goes with people's labor activities in the whole day, integrates the moments of life of Zhuang nationality. Such working song has broad themes, vivid and various plots, fresh and alive characters, complete and full stories. In virtue of thought system of working songs, the song creation will have an expansion space in new form, which can show more life-like fine view, so as to attract more people who love life and feel life to listen.

\section{THE STATUS QUO OF THE INHERITANCE OF ZHUANG FolK SONGS IN THE SONG CREATION}

How to protect and develop Zhuang folk songs and promote the intangible cultural heritage is something we should attach great importance to, as well as a problem that the national musicians should think about. After studying the inheritance of Zhuang folk songs, it is not hard to find that we should pay attention to dealing with the following problems in a scientific way if we want to effectively inherit the Zhuang culture in song creation.

\section{A. Insufficient Awareness of Inheritance of Zhuang Folk Songs}

As the awareness of pursuing material life has gradually been improved, the permanent population in the places where the Zhuang people gathers has been on a decline. In particular, nowadays, due to the rapid development of coastal economy and an increasing demand for labor, the number of migrant workers constantly increases and most of left-behind people are those who are old, weak, ill or disabled. Under this premise, the inheritance of Zhuang folk songs is confronted with unprecedented bottleneck. Migrant young adults have stopped using folk songs to express their emotions in the hustle and bustle of metropolis, and the melody that has been passed down for thousands of years is gradually fading from their memory. The main reasons include the lack of awareness of Zhuang folk songs, neglect of the inheritance value and function of Zhuang folk songs and forgetting of the effect of Zhuang folk songs in carrying forward the Zhuang history. As a result, people no longer pay attention to the study and inheritance of folk songs, and will not even associate them with song creation. This is horrible for the human civilization eager to carry forward and inherit the national culture. It is the sorrow of Zhuang folk songs as well as a dilemma of national culture.

\section{B. Insufficient Platforms for the Inheritance of Zhuang Folk Songs}

The reason why we have not formed a good sense in the inheritance of Zhuang folk songs lies in the insufficient understanding of Zhuang folk songs. The traditional Zhuang folk songs inherit the history and knowledge culture of Zhuang nationality. In the cultural inheritance system without unified texts, these songs have become the wise sayings of human life. The Zhuang compatriots have made continuous progress with the revelation of life and created a rich and brilliant Zhuang culture. However, along with the scientific and technological development in modern society, more and more new things have been brought into the village of Zhuang nationality in the information age. The update of information has enabled the Zhuang nationality to accept new things quickly, which greatly shocks the traditional civilization. People are not aware of the impact of modern civilization, have not carried forward history and culture through modern civilization, and have not scientifically built a platform for the inheritance of Zhuang folk songs. To make more people know and listen to Zhuang folk songs is a major difficulty in the inheritance of Zhuang folk songs at this stage. In order to better protect the traditional music forms in Zhuang folk songs, we must collect and collate the folk music materials of the Zhuang nationality, apply them to musical creation, and make a promotion and propaganda, so as to effectively alleviate the pressure of protection and inheritance.

\section{Insufficient Integration of Zhuang Folk Songs}

Zhuang folk songs should not only follow traditional thinking, but also cater to the modern development trend. Only by fully integrating with modernity and realizing the effective fusing of tradition and modernity can we ensure that Zhuang folk songs both spread and carry forward Zhuang culture and are loved by modern teenagers. However, in the modern development of Zhuang folk songs, people have not focused on satisfying the needs of modern society, and failed to optimize the transmission form of Zhuang folk songs through modern resources and the development situation of modern art. As a result, although Zhuang folk songs are highly artistic and ornamental and have a strong education significance and spiritual guidance, they have little influence on the people and a narrow audience, which waste their own advantages, and are in danger of disappearing in history. 


\section{The Strategy For the DEVELOPMENT OF ZHUANG FOLK SONGS IN SONG CREATION}

Aiming at the problems faced in the inheritance and development of Zhuang folk songs in song creation, a scientific solution strategy should be formulated, and the following also should be implemented:

\section{A. To Expand the Team of Inheriting and Protecting Zhuang Folk Songs}

The folk song culture of Zhuang nationality is deeply entrenched in Zhuang minority region as well as a cultural treasure for the Zhuang people. The inheritance and development of Zhuang folk song culture, led by the Zhuang nationality gathering area, should start from the expansion of inheritance and protection team of folk songs. In this regard, the Zhuang nationality gathering areas and other places must strengthen the cultivation of inheritors of Zhuang folk songs, develop the interest of young people in Zhuang minority region and even in the whole country in Zhuang folk songs by means of quality-oriented education, thus creating an atmosphere and team for inheritance of Zhuang folk songs. On this basis, we should lay stress on the organic integration between song creation and style of Zhuang folk songs, ingeniously combine elements of Zhuang folk songs with creation thinking of modern songs, and fuse contemporary national style into the song creation, so as to build classic folk songs with the flavor of the times. As a result, young people can be attracted and then devote themselves to the development and inheritance of Zhuang folk songs, which is the key to the inheritance and development of Zhuang folk songs in song compilation.

Moreover, the inheritors of Zhuang folk songs should seize the opportunity of putting the Zhuang culture into practice, make promotion and publicity through all possible practices, and gradually enlarge the influence of Zhuang folk songs starting from themselves. Overall, the construction of team of inheritance and protection of Zhuang folk songs requires the active cooperation of education department, collaboration of song creation teams, and unremitting efforts of folk song inheritors, so as to provide a support for the expansion of folk song inheritance and protection team and truly ensure the increase of folk song inheritors and construction of folk song protection organizations.

\section{B. To Enhance the Consciousness of Inheritance and Development of Zhuang Folk Songs}

The premise of expanding the inheritance and protection team of Zhuang folk songs should promote the inheritance and development consciousness of Zhuang folk songs. It can be said that the construction of any good team for inheriting and protecting folk song creation should deeply implement the inheritance and development consciousness. Only by possessing scientific inheritance and development consciousness can ensure the scientificity of construction of folk song inheritance and development team and truly lay a solid foundation for future inheritance and development work. In this regard, the author believes that raising the awareness of inheritance and development should proceed from four perspectives: first, intangible cultural heritage organizations should give more publicity to the protection of intangible cultural heritage, and promote folk song culture in villages, locality, and even the whole country; second, local governments should highlight the importance of cultural inheritance, and cooperate with non-heritage organizations to expand the influence of propaganda on the basis of intensifying consciousness learning; third, local universities, primary and secondary schools and other educational institutions should bring folk songs into classroom, encourage students to apply Zhuang folk songs to song creation, keep abreast of the times, create songs in line with current audiovisual habits in a way that is more acceptable to young people, and then make propaganda through performances, competitions, etc.; fourth, community village committee and other organizations assist with the propaganda of relevant knowledge of Zhuang folk songs, enable teenagers lay a foundation from an early age, and make the consciousness of folk song inheritance and development deeply rooted in their heart by emphasizing the importance of folk songs.

\section{To Create a Platform for the Inheritance and Development of Zhuang Folk Songs}

Currently, in terms of imperfect platform construction in the inheritance and development of Zhuang folk songs, the author believes that the following should be implemented:

- To build a scientific platform for inheritance and development, we should stress the construction of entity platform. Meanwhile, combined with the network environment, we also should create a network platform for dissemination and promotion. The construction of entity platform needs to start with the establishment of folk song learning institutions, folk song research institutions and cultural exhibition and creation institution. We should take the construction of Zhuang culture protection platform as the key with the aid of government forces and social resources, and closely integrate cultural protection with song creation.

- Incorporating the thinking of tourism development can effectively introduce foreign capital. We will build venues for publicizing the folk song culture of Zhuang nationality and experience centers for their compilation in the areas where the Zhuang people gather to increase scenic spots in the Zhuang minority region and better disseminate the folk song culture. Relatively, for the regional cultural customs, festival customs and religious customs of the Zhuang nationality, we will urge the development of various folk song singing activities, and closely integrate them with cultural promotion and tourism, to expand the influence of folk song culture and ensure the inheritance of folk song culture.

- We will record the performances of folk song artists in the forms of video and audio with the help of unboundedness and shareability of network while constructing a scientific cultural experience museum, 
and then assemble them into resources to share them on the network. Besides, we will upload the promotion video by virtue of the organizational component network propaganda platform of entity propaganda organization so that more people can understand the Zhuang folk song culture.

\section{To Promote the Integration of Traditional and Modern Zhuang Folk Songs}

The folk song culture of Zhuang nationality originates from the life of Zhuang compatriots, so it fully reflects the spirit and art extracted from their daily lives. To popularize and carry forward the Zhuang folk songs, we will fuse them with modern art, and under the thinking concept of modern compilation and creation, create a scientific folk song compilation system, integrate traditional folk song culture, and mix modern compilation technology, so that the new songs can inherit the warm, simple, romantic and sincere personality of Zhuang folk songs and become a channel for historical cognition, a tool for recreation and entertainment, and a means of displaying the national soul.

Specifically, in order to ensure the inheritance of Zhuang folk songs, fully integrate the artistic treasures into the mainstream culture and make more people understand and familiarize with Zhuang folk songs, we will fully integrate traditional and modern thinking with the inclusive power of the folk songs, create a new singing style for folk songs and popular folk songs, and make them an excellent national culture carried forward by modern media.

\section{CONCLUSION}

To sum up, Zhuang folk songs have a long history, and rich forms and themes, which give much inspiration to song creation. Its inheritance and development are of great significance to modern society. Through this study, the author strives to do his part for the scientific inheritance and effective promotion of Zhuang folk songs, and constructs a road to inherit and develop Zhuang folk songs.

\section{REFERENCES}

[1] Zhao Shimin. How does "Folly Song Yeast" Ferment in the Creation of Shengmao Songs?[J]. Art of Singing, 2016, (09): 27-33. (in Chinese)

[2] Wang Yanfang. The Penetration of Mongolian Folk Songs in Modern Songs [J]. Practical Electronics, 2014, (23): 273. (in Chinese)

[3] Xiaohong. Study on the Inheritance and Development of Northern Shaanxi in Vocal Music Teaching in Local Universities [J]. Education in Shaanxi (Higher Education), 2014, (10): 21-22. (in Chinese)

[4] Shi Yong. Research on the Application of Jiangsu Folk Songs in the Creation of Contemporary Pop Songs-A Case Study of Jasmine and Meng Jiangnv [J]. Symphony (Journal of Xi'an Conservatory of Music), 2015, (03): 127-133. (in Chinese) 